\title{
A detailed study on design, fabrication, analysis, and testing of the anti-roll bar system for formula student cars
}

\author{
Sachin Sunil Kelkar ${ }^{1} \cdot$ Puneet Gautam $^{1} \cdot$ Shubham Sahai $^{1} \cdot$ Prajwal Sanjay Agrawal $^{1}$ (D · R. Manoharan ${ }^{1}$
}

Received: 9 September 2020 / Accepted: 27 January 2021 / Published online: 10 February 2021

(c) The Author(s) 2021 OPEN

\begin{abstract}
This study explains a coherent flow for designing, manufacturing, analyzing, and testing a tunable anti-roll bar system for a formula student racecar. The design process starts with the analytical calculation for roll stiffness using constraining parameters such as CG (Center of Gravity) height, total mass, and weight distribution in conjunction with suspension geometry. Then, the material selection for the design i.e. Aluminum $7075 \mathrm{~T} 6$ is made based on parameters such as density and modulus of rigidity. A MATLAB program is used to iterate deflection vs load for different stiffness and shaft diameter values. This is then checked with kinematic deflection values in Solidworks geometry. To validate with the material deflection, finite element analysis is performed on ANSYS workbench. Manufacturing accuracy for the job is checked using both static analysis in lab settings and using sensors on vehicles during on-track testing. The error percentage is found to be $4 \%$ between the target stiffness and the one obtained from static testing. Parameters such as moment arm length, shaft diameter and length, and deflection were determined and validated. This paper shows the importance of an anti-roll bar device to tune the roll stiffness of the car without interfering with the ride stiffness.
\end{abstract}

Keywords Anti-roll bar $\cdot$ Suspension geometry $\cdot$ Formula student $\cdot$ Design and manufacture $\cdot$ Simulation

\section{Introduction}

Vehicles are generally classified into two types on-road and off-road vehicles. This research is focused on on-road vehicles specifically formula student racecar. Formula Student is an international design competition where students design, build an open-cockpit race car and compete in various static and dynamic events. Each team in Formula Student is broadly categorized in suspension, aerodynamics, powertrain, chassis, and electrical departments. This research operates under suspension department workflow while coordinating with other departments. The designing of a Formula Student car is carried with a single goal in mind i.e., to achieve the best lap time possible. Every other design concept and goal is sketched out using the former as the central idea. Suspension design plays a vital role in the complete designing process as it determines how the input from other systems such as powertrain and aerodynamics reach the ground level and helps in the achievement of goals. The suspension system controls the dynamics of the tire, which ultimately affects the amount of grip of the car to the ground that is responsible for the overall control of the racecar. This system is designed to control the basic motions of the vehicle in 3-Dimensional space that are lateral, vertical, and longitudinal forces acting on a car, also the control of roll and the moments on those axes. The position where these forces are acting on the racecar is shown in Fig. 1.

It is of utmost importance to control these vehicle movements independently so that the car can be tuned more efficiently without compromising any of the parameters. Firstly, the pitching movement of the vehicle can be

Prajwal Sanjay Agrawal, agrawalprajwal007@gmail.com | ${ }^{1}$ Vellore Institute of Technology, School of Mechanical Engineering, Vellore, Tamil Nadu 632014, India. 


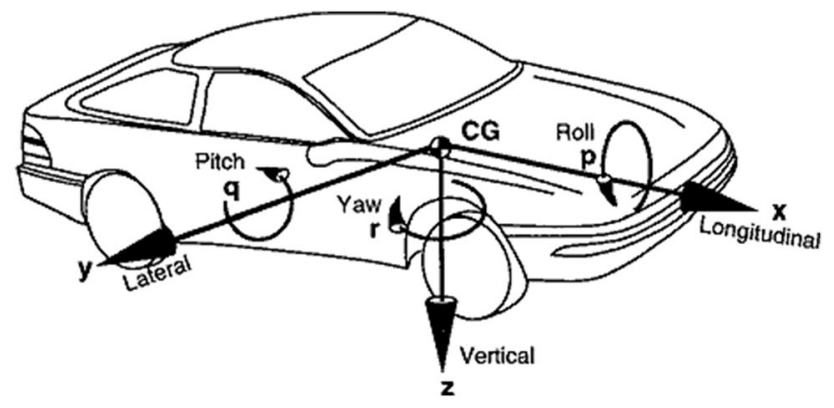

Fig. 1 Degrees of freedom of a car. Reprinted with permission from [1]. Copyright SAE International 1992

controlled using the stiffer spring setup, which in result also affects the roll stiffness of the vehicle. Later, the introduction of the anti-roll bar induces roll stiffness in the vehicle without making a compromise on the ride stiffness. These anti-roll bars are generally modeled as U-bar or Z- bar type designs. Figure 2 depicts the anti-roll bar connection with the suspension geometry of the car. It also shows how the other suspension subsystems like the control arms, dampers system, and others are interlinked.

The anti-roll bar grabbed the attention of many researchers after 1997 when the SAE (Society of Automotive Engineers) spring design manual gave an overview of designing an anti-roll bar. However, the scope of this manual was limited to commercial and road vehicles, so it's utilization was also limited [3]. Later Zhang and co-workers in 2009 displayed simulations using ADAMS multibody analysis, this procedure was used to calculate stiffness for an anti-roll bar using the Craig Bampton method which was implemented in the software. This research also studied the effect of an anti-roll bar for a single stiffness value [4]. In addition to this in 2011-12, Pravin and co-workers showed the procedure for designing an anti-roll bar for Mc Pherson strut-type suspension, the limitation of this system is its design type as the parameters like motion ratio, and mounting points were constrained within the structure [5]. So to have this limitation eradicated in 2013
Wang and co-workers demonstrated a way to tackle the apparent drawback of using an anti-roll bar, which limits the amount of wheel travel on an uneven surface and particularly in articulation mode. But at the same time, they suggested that an anti-roll bar is useful in the case of high-speed cornering which is desired in our application [6]. Apparently, in the same year, Ribeiro and Silveira tried to demonstrate the geometrical parameters that alter the stiffness of the anti-roll bar. The drawbacks of this paper were the variables such as the position of the bushing, cross-section, and the opening angle of the shaft which were not taken into account [7].

To overcome these drawbacks in 2015 Shi and coworkers displayed the effect of positioning and usage of anti-roll bar on a passenger bus, their work also includes the tire characteristics, and static testing which was carried out to demonstrate the achievement of desired results for the design and experimentations [8]. Later in the same year Zhou and co-workers demonstrated the use of interconnected 4 wheel suspension systems, for 2 axle vehicles, this was done in the case of off-road vehicles especially, in the warp mode, the limitation of this research was the wheel contact patch which eventually caused wheel lift [9]. Whereas Emre Sert and co-workers in 2016 demonstrated the sensitivity of using the anti-roll bar system in heavy vehicles that are prone to rollover conditions. They tried 3 different anti-roll bars and 2 leaf spring setups firstly in an ADAMS car, and eventually, a bench test was carried out [10]. Also, Koundinya and coworkers demonstrated the advantage of using an active roll control unit by using hydraulic actuators and simulating the model on IPG (company) car makers while coupling it with the MATLAB-Simulink model, it also includes simulating extreme maneuvers [11]. Later in 2018, Zhang. $Y$ and co-workers worked on an active anti-roll system by using a switched reluctance motor and a harmonic gear reducer, the model was developed on MATLAB-Simulink in a closed-loop system that calculates anti-roll torque in real times [12]. Further in 2019, Yulong Liu's research incorporated an important parameter the steering system which
Fig. 2 The anti-roll bar on a commercial vehicle. Modified from [2]

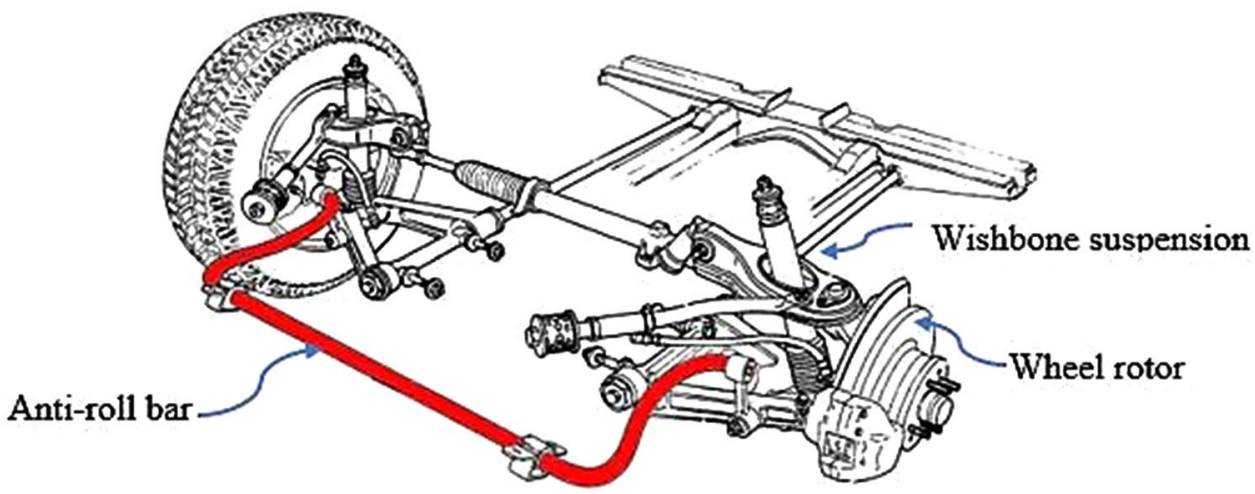


is often neglected. This research takes upon the dynamic game theory between two systems that are active steering and active roll control and it also tries to find the optimal solution by finding the nash equilibrium for this system [13]. The recent advances in 2020, by V. Mohavavel and co-workers, demonstrated the use of ANSYS to analyze the deflection of anti-roll bar structure in $x, y$, and $z$-axis, it also emphasizes developing the hollow tubular structure to save weight, the research, however, misses an elaborate explanation of how the mathematical models are generated and to calculate the essential parameters of the antiroll bar [14]. So, the anti-roll bar system design, analysis, and manufacturing for a formula student race car is a not well-studied topic with the help of this particular study, and we aim to develop tunable anti-roll bar devices for individual axles for a Formula student race car. The primary aim of this research is to achieve the desired roll gradient of the chassis as it affects the outputs of other systems of the vehicle. Hence our goal is to design, analyze, and manufacture a tunable anti-roll bar for push rod type suspension systems.

In this paper, firstly an explanation of the theoretical calculation for the anti-roll bar is carried out, by highlighting the mathematical modeling for the system using dimensional calculations. Then an overview of CAD modeling and finite element analysis (FEA) is given with complete supports and force constraints. Next, we describe the procedure for static testing and on-track testing and a comparison of the data obtained from these tests utilizing the theoretical calculations in order to check for errors in manufacturing and FEA. Before moving onto the conclusion an insight on results and future perspective is given.

\section{Mathematical modeling, analysis, and manufacturing process}

This section mainly focuses on generating and deriving the essential mathematical equations that are required to parameterize the motion of a vehicle during cornering conditions. Based on these equations, and constraints the dimensions for the anti-roll bar are calculated. Additionally, the roll of the chassis affects the amount of aerodynamic load produced, camber values on tires, roll induced steering, and driver comfort. These parameters individually or collectively affect vehicle performance. It is observed in racing situations that performance varies from track to track (due to the track structure, elevation, and other external factors) it becomes cardinal to adapt to the given condition to churn out maximum performance from the vehicle. Hence this research aims to develop a tunable anti-roll bar to accommodate different track requirements.

\subsection{Forces and moments during cornering}

Mathematical models play an essential role in the designing of an anti-roll bar system. A few terminologies are needed to be defined before analyzing the effect of forces and moment on the vehicle. Firstly, the roll center which is an instantaneous point about which the axle tends to roll. Secondly, the roll axis which is an imaginary axis (in the side view of the vehicle) created by joining the front and rear roll center. When a vehicle moves in a circular path, the centrifugal force acts on the center of gravity and this force then produces a roll moment about the roll axis. This moment results in the rolling maneuver of the vehicle. Figure 3 depicts all the necessary forces and moments acting on the vehicle.

Where $\varphi$ is the roll angle, $h_{r}$ is the rear roll center height, $h$ is the CG height, $F_{z o}$ and $F_{z i}$ are normal reactions on outer and inner tires, respectively. Mg is weight acting downwards, $t$ is the track width, $M_{S}$ is the roll moment, $F_{y i}$ and $F_{y o}$ are lateral forces on inner and outer tires, respectively.

\subsection{Calculating roll stiffness}

Once the ride frequencies $(f)$ are fixed for each axle, the corresponding roll stiffness which can be obtained is calculated by firstly calculating ride stiffness $k$ where $m$ is the mass on the axle as shown in Eq. 1 and Eq. 2: [15, 16]

$f=\sqrt{k / m}$

$k_{\varphi}=\frac{k * t^{2}}{2}$

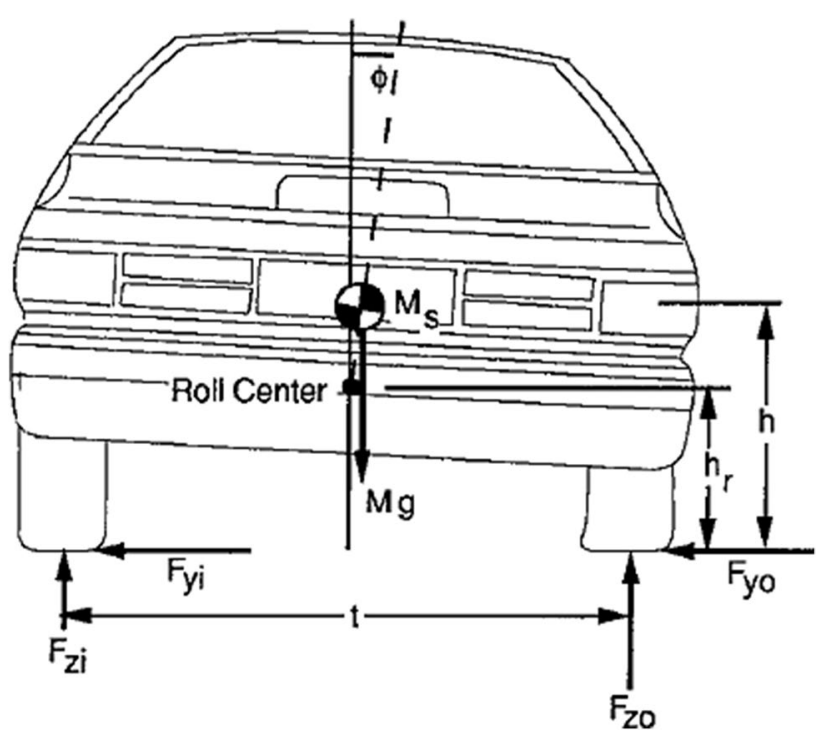

Fig. 3 Forces and moments acting on a vehicle. Reprinted with permission from [1]. Copyright SAE International 1992 
where $k_{\varphi}$ is the roll stiffness, $k$ is ride stiffness (or ride rate), and $t$ is the track width of the given axle.

Then a quantity called "Roll Gradient" is determined using Eq. 3, which relates the amount of vehicle roll desirable during concerning unit $g$ (lateral acceleration normalized by $\mathrm{g}$ (gravitational force) $=9.8 \mathrm{~m} / \mathrm{s}^{2}$ ) of lateral force. The roll gradient is generally kept in the range of (0.5-1) for race cars and high-performance vehicles, especially for those cars that generate downforce using aerostructures. This is done by utilizing a lower magnitude roll gradient that eventually results in less roll of chassis in the corners. Hence, resulting in a minimal loss of downforce and the available lateral force [17].

$\frac{\phi}{A_{y}}=\frac{-W * H}{K_{\phi d e s}}$

where $\phi$ is the roll angle, $K_{\phi \text { des }}$ is desired roll stiffness, $W$ is the total weight, $A_{y}$ is the lateral acceleration of the vehicle and $H$ is the normal distance between the roll axis and center of gravity (the value "h-hr" in Fig. 3). The roll gradient is fixed for a system, and the desired roll stiffness for a particular geometry is calculated.

Considering a single tire system (also called a quarter car model), 2 springs are acting in a series combination that is, a tire spring, and an actual spring on the sprung mass. When the anti-roll bar is added to the system, the additional spring (anti-roll bar) acts in parallel with the suspension spring and both in series with the tire, as shown in Fig. 4

The additional roll rate required to meet the desired roll gradient [16] is calculated according to Eq. 4:

$K_{\phi A}=\frac{\pi}{180}\left\{\frac{K_{\phi \text { des }} K_{T}\left(\frac{t^{2}}{2}\right)}{\left[\frac{K_{T}\left(\frac{t^{2}}{2}\right) \pi}{180}-K_{\phi \text { des }}\right]}\right\}-\frac{\pi K_{w}\left(\frac{t^{2}}{2}\right)}{180}$

where $K_{\phi A}$ is an additional roll stiffness required for using anti-roll bars and $K_{T}$ is the tire stiffness in $\mathrm{N} / \mathrm{m}$, this is the total stiffness required on the chassis, and then it is further divided into front and rear stiffness accordingly.

$K_{w}$ is the wheel rate, which is defined using Eq. 5:

$K_{w}=k * M R^{2}$

where $k$ is the ride rate defined earlier, and MR is motion ratio, the motion ratio is defined using Eq. 6

$M R=\frac{\text { Wheeltravel }}{\text { springtravel }}$

where $K_{T}$ is the tire stiffness or tire rate. [18]

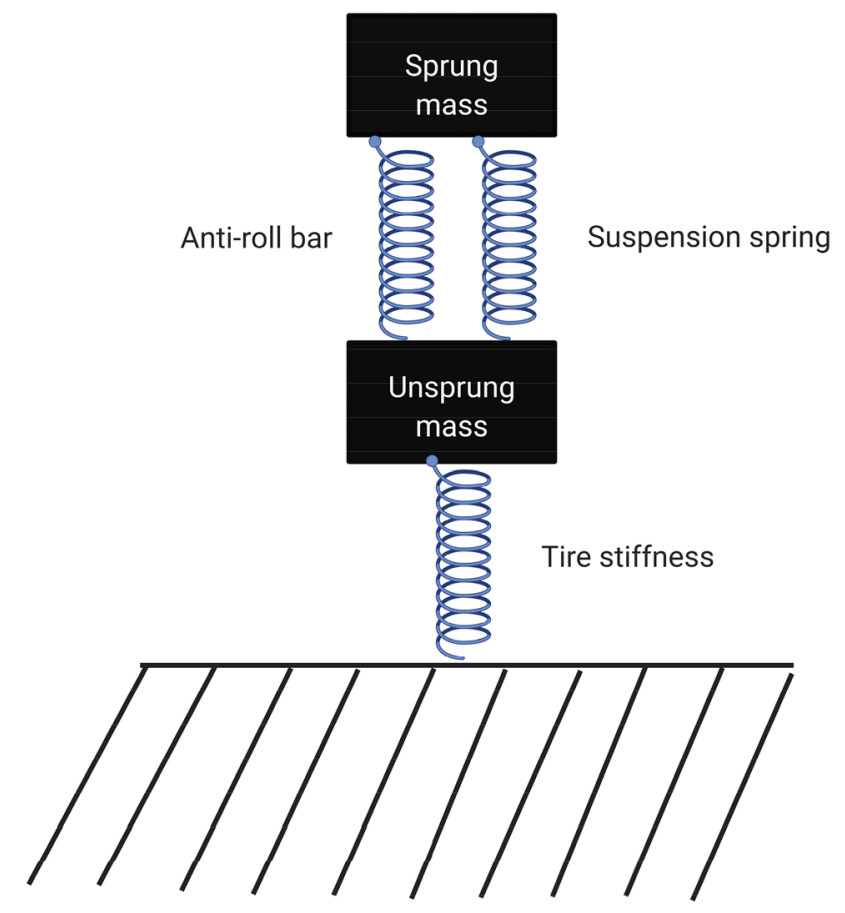

Fig. 4 Quarter car model can be condensed in the given springmass model

\subsection{Designing and calculating the shaft dimensions}

For designing the anti-roll bar, the following steps are followed. Firstly the motion ratio for the anti-roll bar is fixed for all the calculations (to start with the calculation), in this research it was selected to be 0.38 , this value was selected based on the packaging constraints in the assembly of the anti-roll bar.

Secondly, the calculation for the lateral acceleration of the car when the chassis roll will be $1^{0}$ is done. This calculation is made using Roll Gradient as it is the value defining roll of chassis per g's of lateral acceleration as defined in Sect. 2.2. Corresponding to this lateral acceleration, the lateral load transfer on each axle is determined using the following equation:

Lateral load transfer $=\frac{m * a * I}{t}$

where $m$ is the mass on the axle, $a$ is lateral acceleration, $I$ is CG height from the ground and $t$ is the track width of the corresponding axle.

As the current system is using a rocker/bell crank arrangement, in a steady-state situation, the moment about the pivot point of the rocker must balance. For balancing, the force acting on the anti-roll bar mounting point is then calculated according to the chosen motion ratio for the anti-roll bar. Later, by iterating the length of 
the moment arm, the torque $(\tau)$ applied on the shaft is iterated by using Eq. 8 i.e.

$\tau=r * F$

where $r$ is the arm length (perpendicular to the application of force), and $F$ is the resultant force on the mounting point.

After determining the torque applied, the additional roll stiffness required ( $\mathrm{N}-\mathrm{m} /$ degree) is compared with the torque achieved at the anti-roll bar (also the resisting moment by Newton's third law) that is calculated to be at $1^{0}$ chassis roll. Subsequently, the motion ratio and length of the shaft are iterated using MATLAB code to equate it to the required value (additional roll stiffness at a given axle). Then, the length of the moment arm is fixed for each iteration. After that, the overall concept of the project including the tunability and the system which is designed for different stiffness setups by utilizing variable-discrete length mounting holes. Lastly, the length of the anti-roll bar shaft is constrained due to cockpit dimensions; hence it is used as the input dimension. These are the steps involved in designing the shaft geometry. After this, the material used for this project is selected to be Al 7075-T6. The material required for this project was purchased from Perfect Metalworks, Bangalore, with a material certification bill.

The cross-section of the shaft is iterated for different diameter values, and by using the given formula in Eq. 9 deflection is checked for each iteration.

$\frac{\tau}{J}=\frac{G * \alpha}{L}$ where $\tau$ is the torque applied, $J$ is the polar moment of inertia, $L$ is the length of the shaft, $\alpha$ is angular deflection, and $G$ is the modulus of rigidity. [19]

The Anti-roll bar geometry is designed on SolidWorks to check the packaging and clearances. The deflection of the moment arm is checked kinematically for wheel travel at lateral acceleration corresponding to $1^{0}$ of body roll. This deflection is checked with analytical values obtained from the above-mentioned equations, for example, if by analytical calculation the deflection of $2 \mathrm{~mm}$ was obtained, by checking the same deflection kinematically, it was observed that the deflection was within $\pm 0.1 \mathrm{~mm}$ range, resulting in the selection of the corresponding shaft diameter. These dimensions are used to model 3D geometry in SolidWorks.

\subsection{Designing individual components for the anti-roll bar:}

As the highlight of this research is tunability in the component, the moment arm (Fig. 5) was modeled with 4 different mounting points (holes) to accommodate a different range of roll stiffness aimed earlier. To hold the structure in place, supporting flanges were designed with press-fit tolerance for deep groove ball bearings (as depicted in Fig. 6), as the device is supposed to undergo torsion and angular deflection. Finally, a shaft structure is extruded with the required dimensions, and then an assembly is made in the software (as shown in Fig. 7) according to packaging constraints in the chassis and with systems in its proximity. The same assembly is used for FEA analysis in ANSYS. All dimensions are in $\mathrm{mm}$.

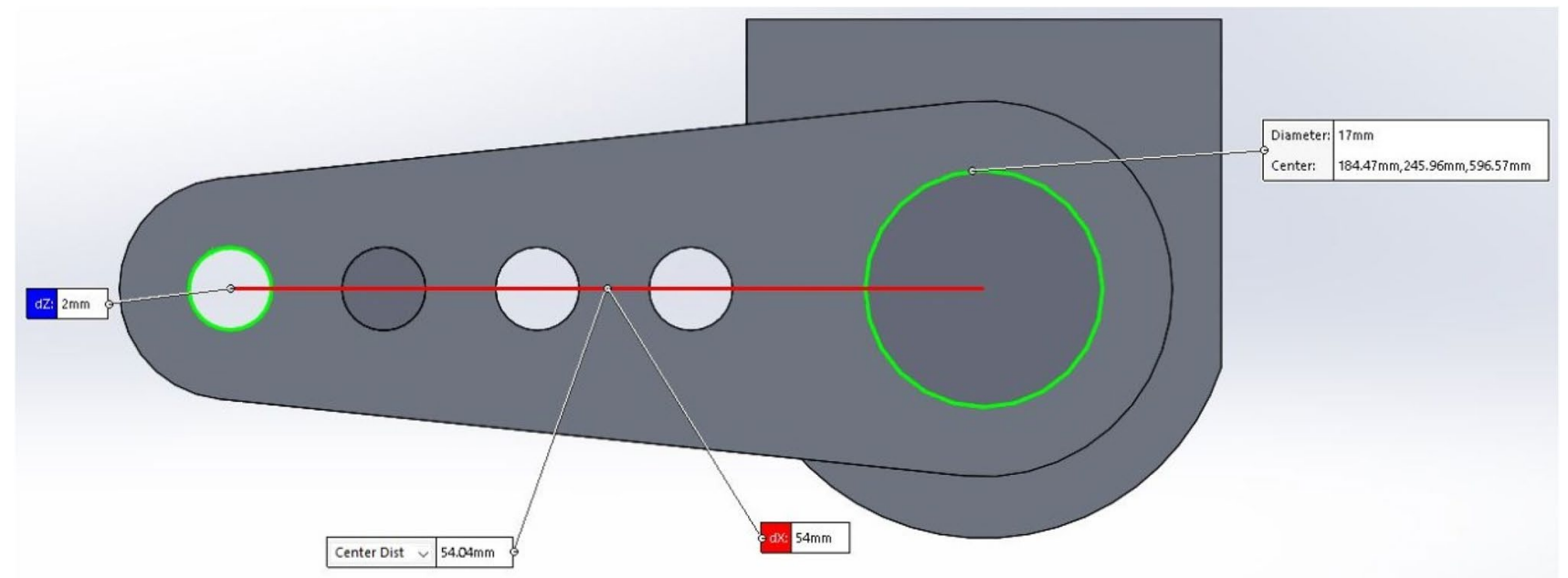

Fig. 5 Moment arm 


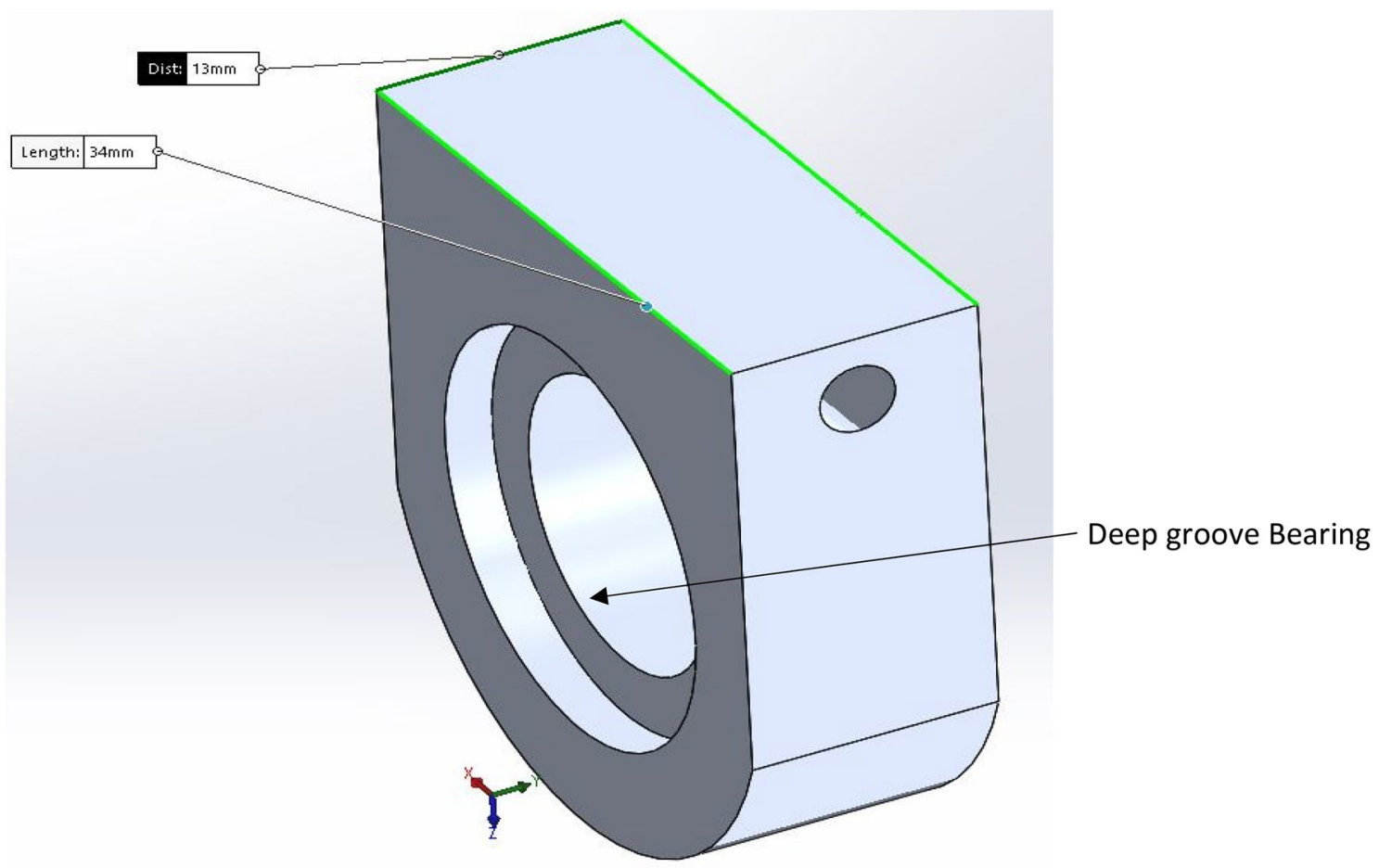

Fig. 6 Supporting flange

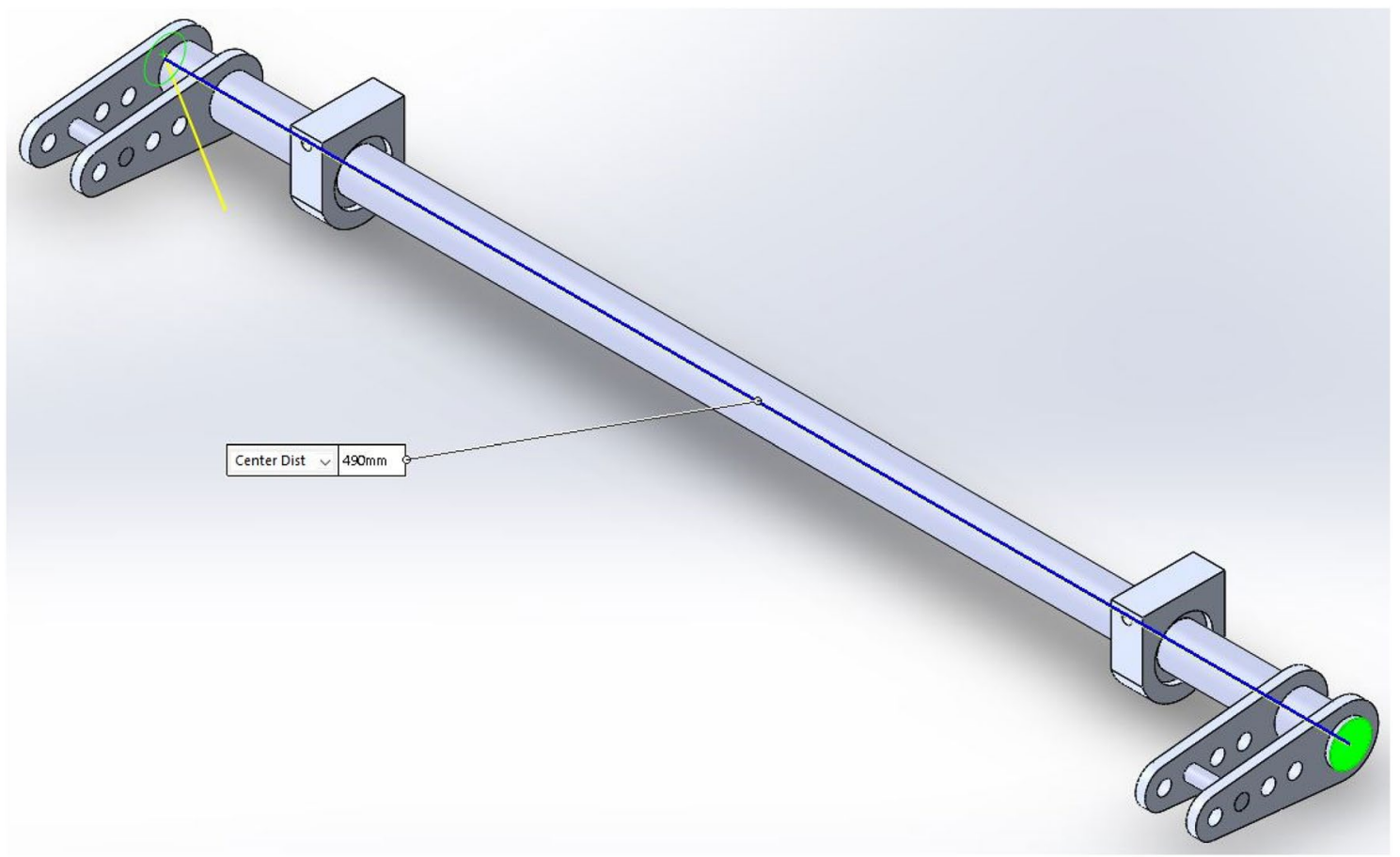

Fig. 7 Anti-Roll Bar assembly 


\subsection{Manufacturing}

As the design operates on fluctuating load cycles, it is essential to select a material that has high fatigue strength and impact toughness. As we know in a formula student race car, weight is of utmost importance, as by increasing weight more power is required to overcome the inertia of material; hence components are designed by keeping in mind the strength to weight ratio, amongst the compared materials such as mild steel, aluminum 6061, and aluminum 7075 T6, only aluminum 7075 T6 has desirable properties as mentioned.

Aluminum 7075 T6 shaft of $20 \mathrm{~mm}$ diameter was purchased from the company as mentioned earlier and was turned down to $17 \mathrm{~mm}$ on the lathe machine in Materials and Manufacturing Laboratory, SMEC, VIT, Vellore. For manufacturing moment arms, 4 mm Al7075 T6 sheets were laser cut on machines with a precision of $25 \mu \mathrm{m}$ at Goodwill industries, Banglore. The supporting flange was machined at GK industries, Vellore using a lathe and vertical milling machines. Hydraulic press at Satyamoorty Industries, Vellore, was used to press-fit the deep groove ball bearing inside the supporting flange. The moment arms were joined on the shaft using the brazing process at a local materials store in Vellore. Hence an overall mechanism of anti-roll bar was manufactured.

\section{Validation and analysis}

The validation of the anti-roll bar system can be given by analyzing the factor of safety (FOS) of the particular components. If the FOS of the designed system is greater than 1, then the components are safe to use and can be manufactured [20]. The analysis of the antiroll bar is carried out in the following order of steps. Firstly, the ANSYS Static Structural package is used for FEA. Then, the assembly is imported as a Parasolid file $(. x+t)$. Later meshing of the constraint is carried out (Fig. 8). Then, the bearing structures are given cylindrical support and remote displacement is assigned 0 for all degrees of freedom for the mounting points on the chassis (Fig. 9). Also, no separation for weld contacts on the shaft was given (Figs. 10,11). Then, a vertically opposite load is applied on the opposite ends of the shaft (Figs. 11, 12). Afterward, the FOS, Von-mises stress, and total deformation are checked. Next, the directional deformation is checked in $\mathrm{Y}$-axis and it is compared with an analytical and geometrical deflection from MATLAB and SolidWorks respectively (for example, at a force of $1441 \mathrm{~N}$, the theoretical deflection from MATLAB is $4.3 \mathrm{~mm}$ and the kinematic deflection in SolidWorks in $4 \mathrm{~mm}$, the deflection in the structural analysis was measured to be 4.08 and $4.11 \mathrm{~mm}$ respectively in opposite arms) (Fig. 13). The value of $~ 2.5 \%$ is decided to accommodate the errors caused due to meshing and contact interactions in the FEA analysis

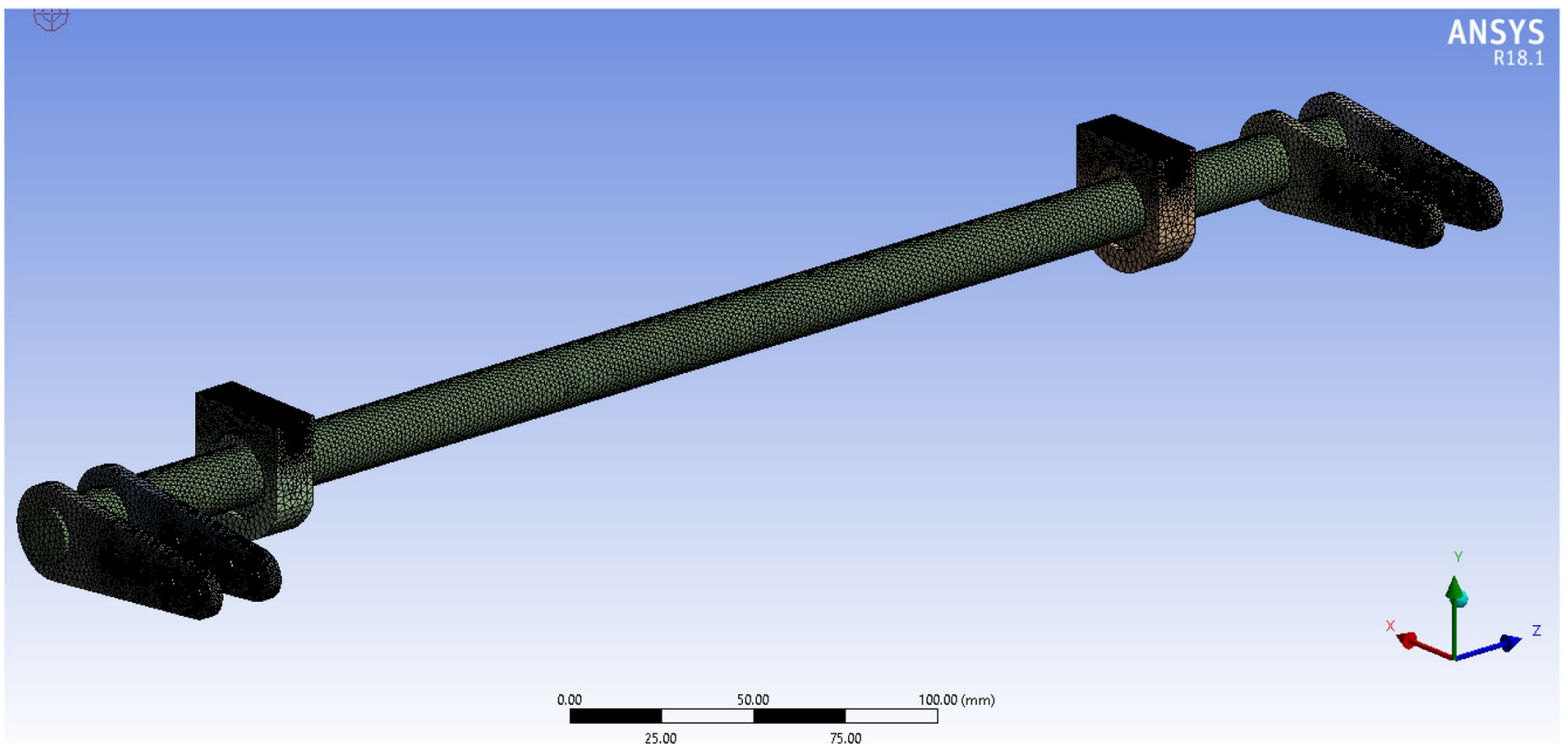

Fig. 8 Meshing (fine/proximity and curvature) 


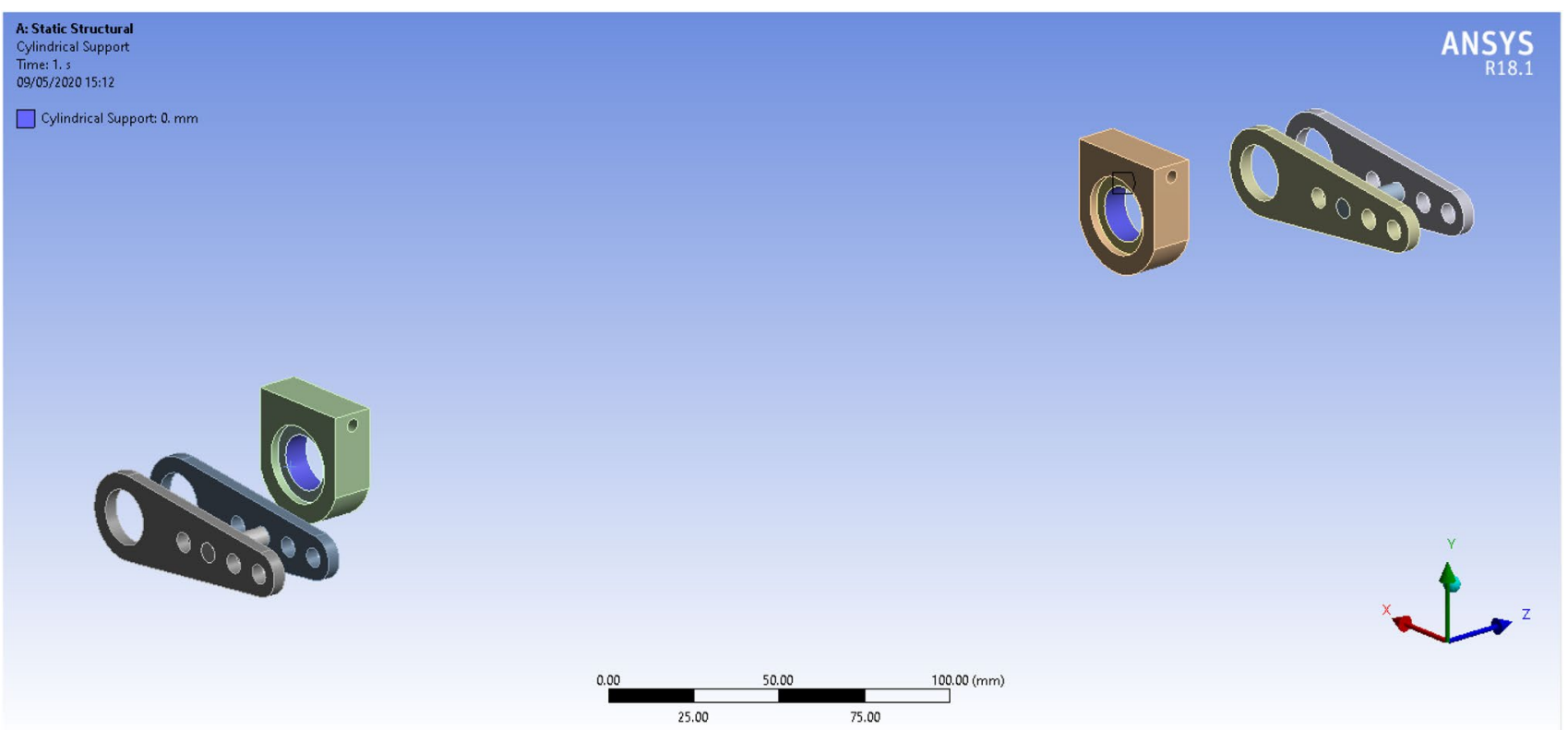

Fig. 9 cylindrical support at the bearing interface

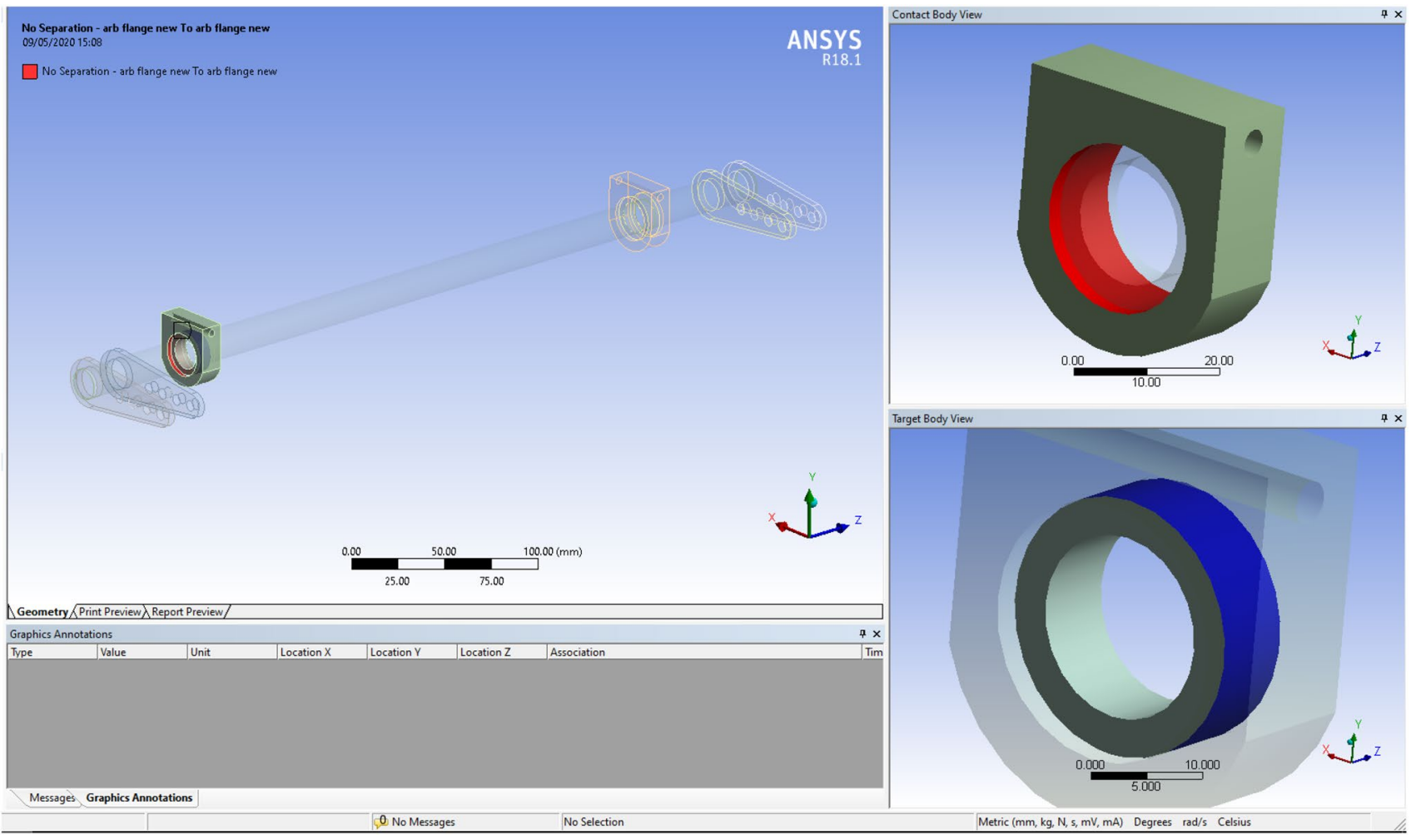

Fig. 10 No separation constraint on the outer race of bearing

[21]. Lastly, the least value of FOS is measured to be 1.6 (Fig. 14) (as a rule of thumb in manufacturing, considering manufacturing defects, material defects, and impact loading in unforeseen cases during operation) and hence was deemed safe for manufacturing [20, 22]. So the FOS gives us proper validation for the entire geometry and the steps are also depicted in Figs. 8, 9, $10,11,12,13$, and 14 .

\section{SN Applied Sciences}




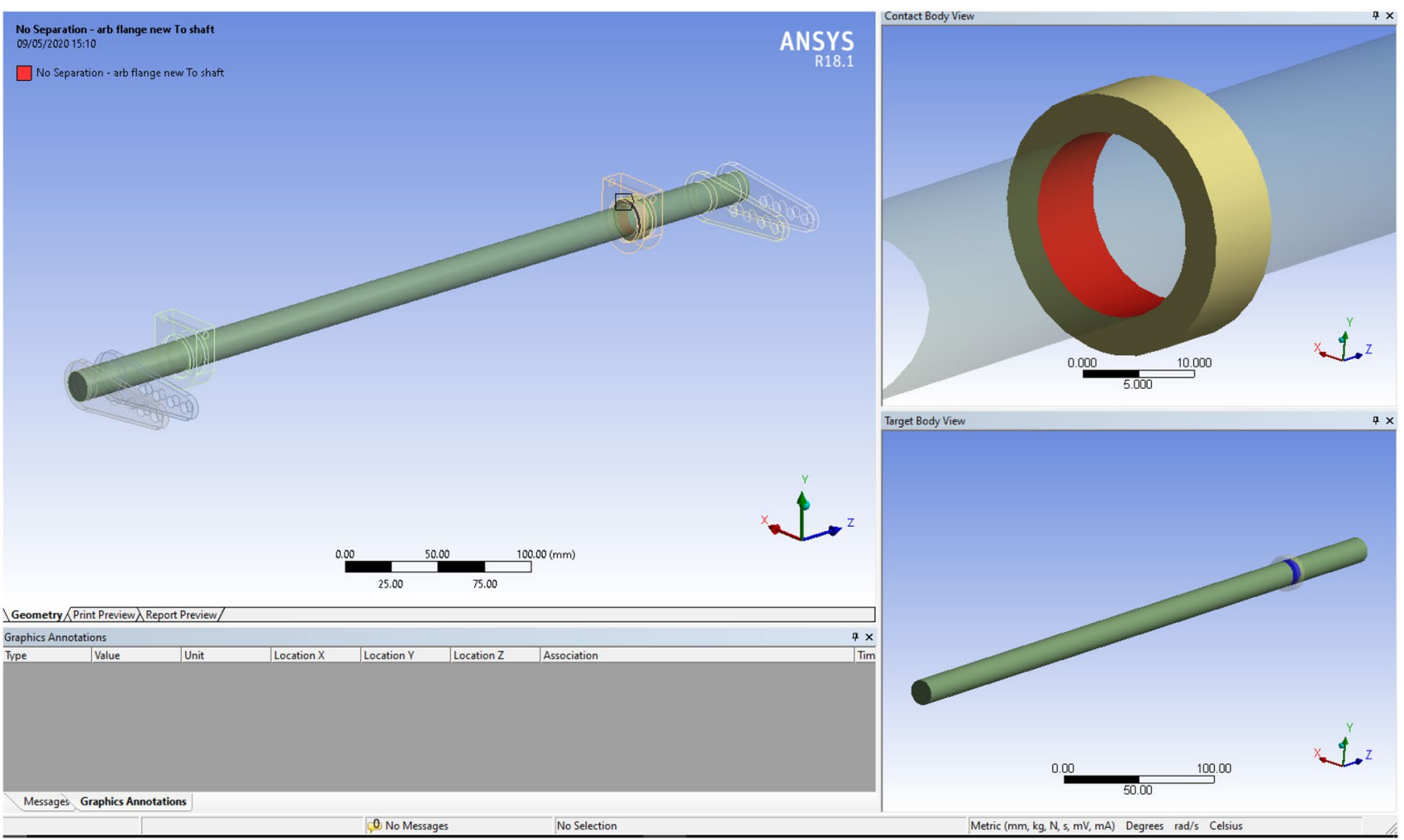

Fig. 11 No separation constraint at the bearing shaft interface

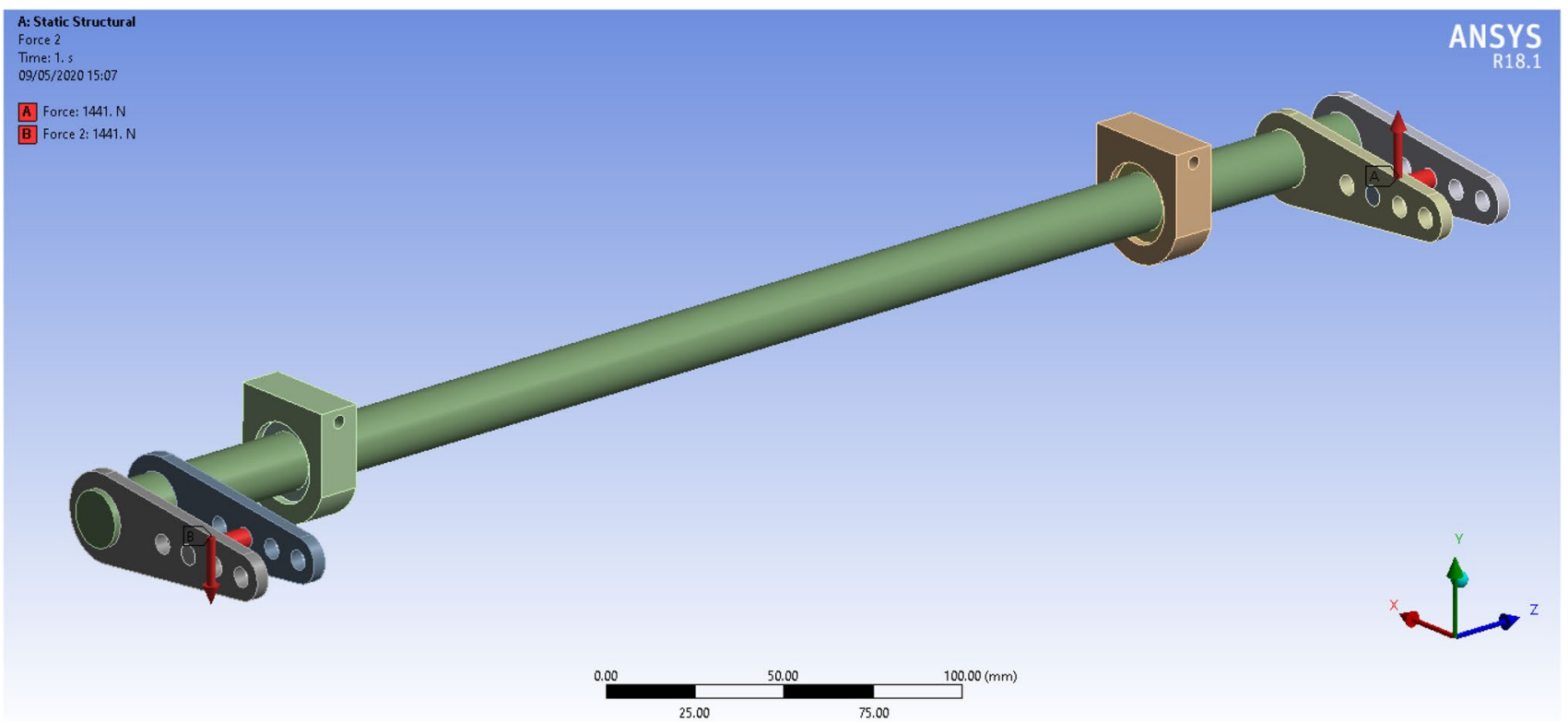

Fig. 12 Opposite equal forces on the moment arms to create torque 


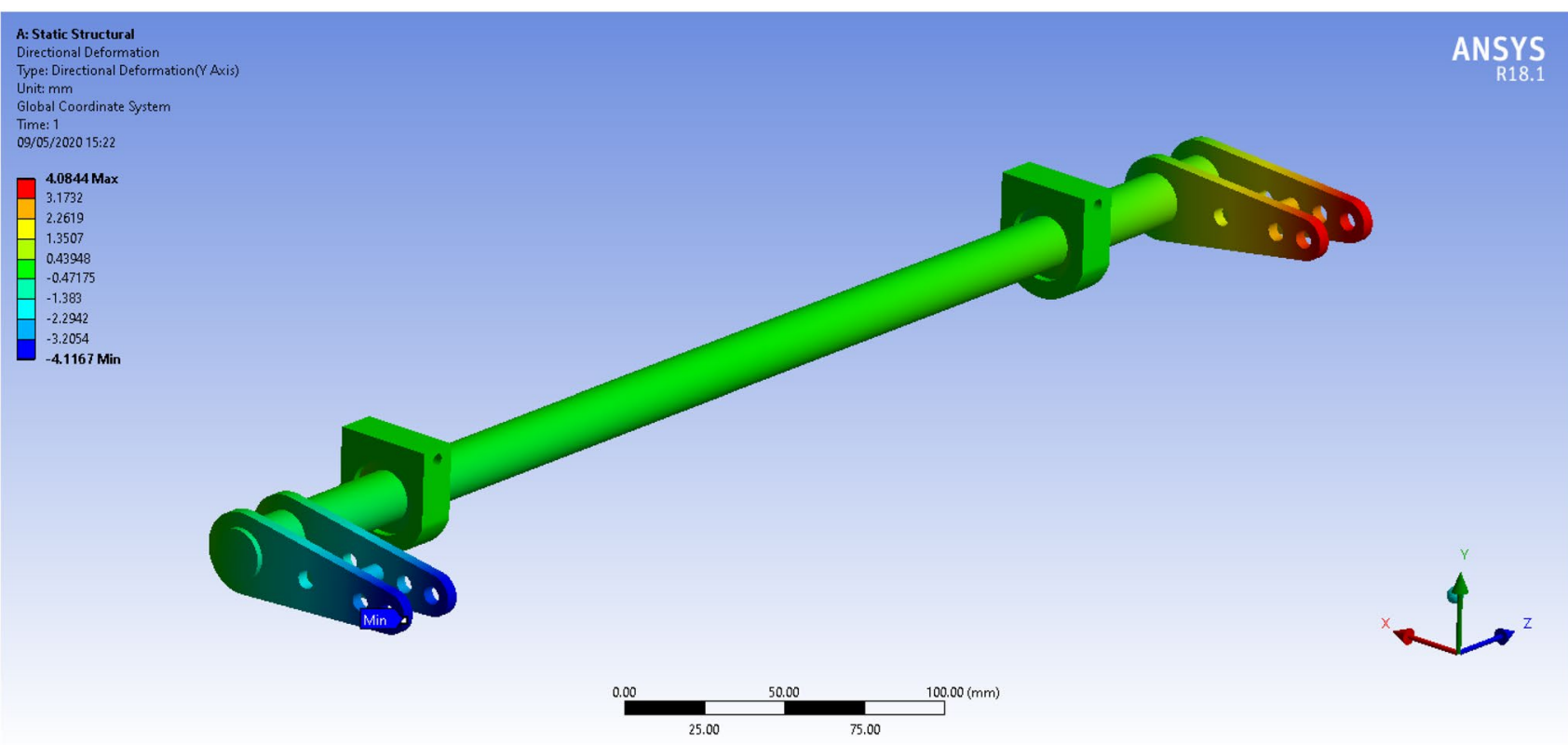

Fig. 13 Directional deformation in the Y-axis

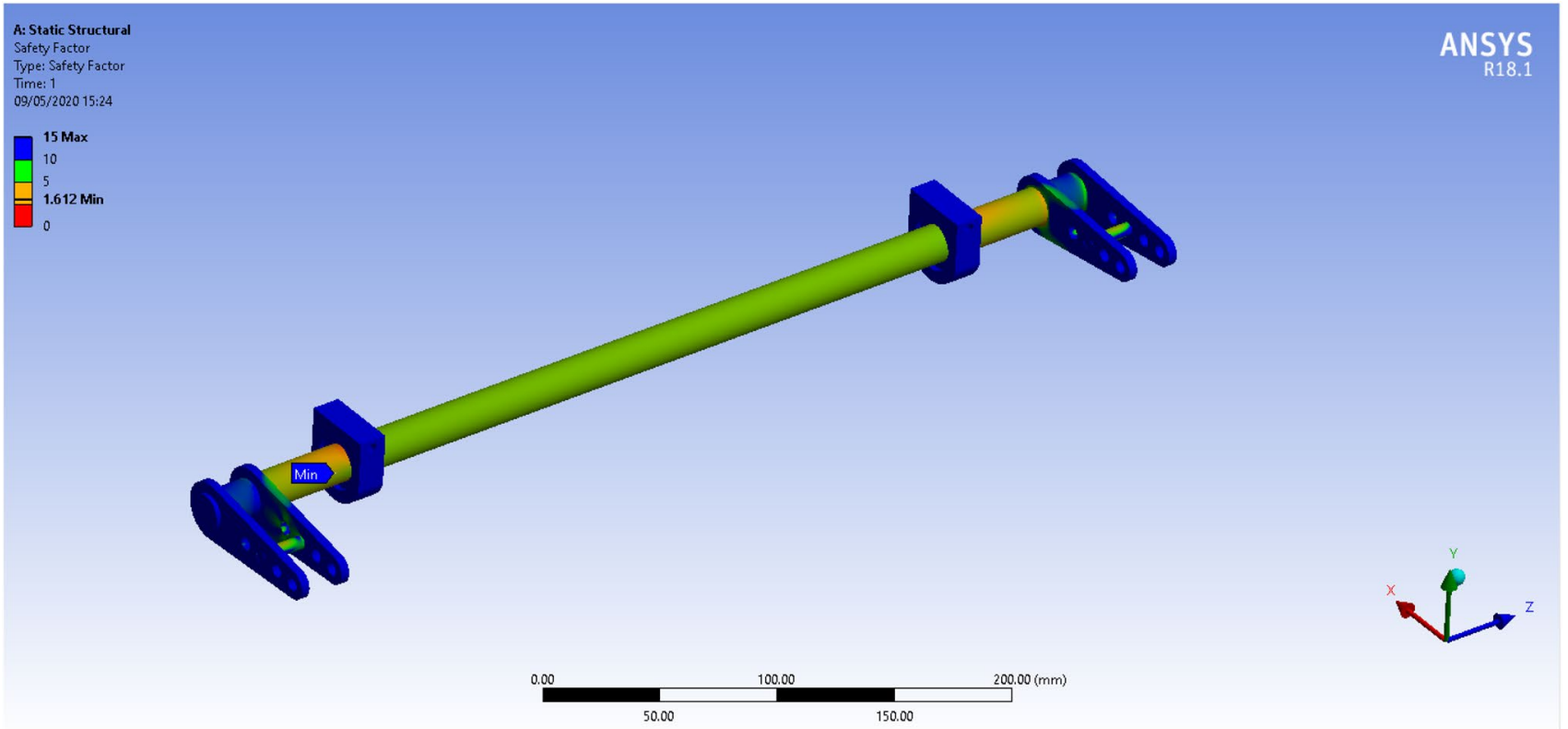

Fig. 14 Factor of safety of the anti-roll bar

\section{Results and discussion}

\subsection{Track testing}

To test the manufacturing accuracy and the effect of using the anti-roll bar on the performance of the vehicle, track testing was carried out by reducing the external influences and errors such as track variations, temperature fluctuations, and driver inputs. The test runs were designed in such a way that the same drivers took alternate lap runs with and without anti-roll bars mounted on them. This reduced the influence of driver style on measured data, and the tire temperatures were reasonably constant between both runs, track parameters were kept constant. Hence these measures ensured that data logged is directly influenced due to changes in vehicle parameters not from external influences. 


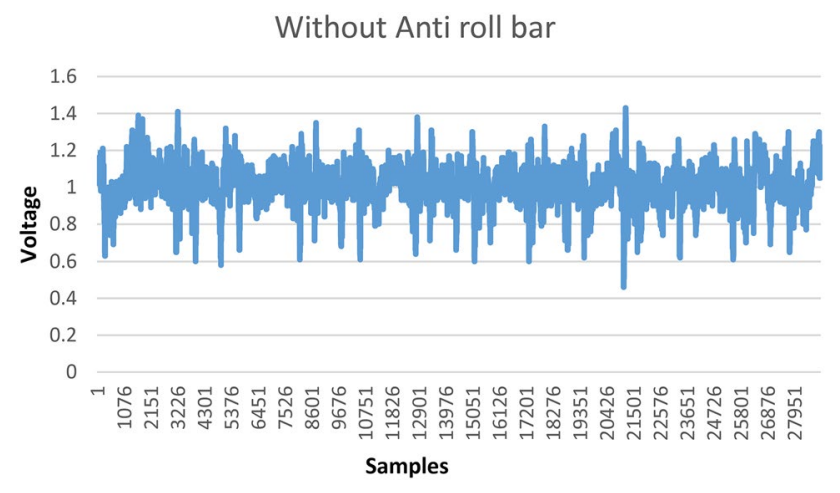

Fig. 15 Potentiometer data without an Anti-roll bar

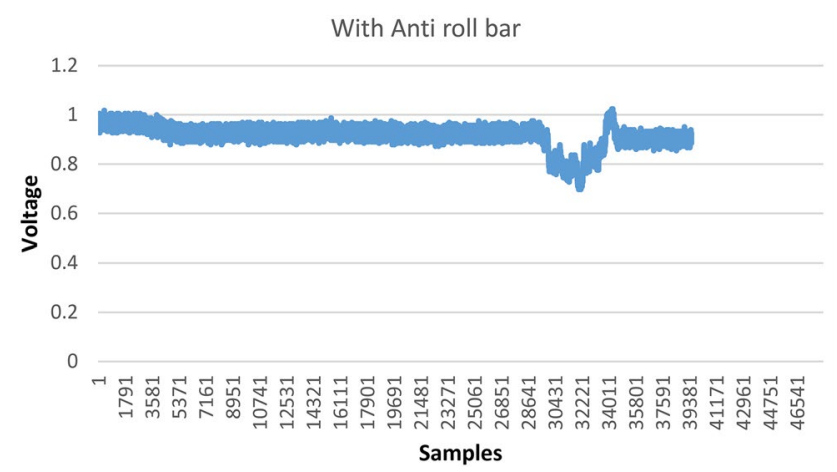

Fig. 16 Potentiometer data with Anti-roll bar

For measuring the effect of the anti-roll bar on vehicle motion, the wheel travel data was logged in the lap run and was compared for both cases. As the anti-roll bar provides additional stiffness to the chassis, the vehicle remains more stable and becomes less "sloppy" in the corners, hence this change is reflected in the wheel travel data plots. The anti-roll bar not only decreases the amount of body roll while cornering but also helps to maintain the stability of the vehicle while a single wheel goes into a bump due to track elevations and unevenness. When a wheel passes over some uneven surface, the anti-roll bar pushes the other wheel in a bump and, as a result, lowers both the wheels. The change in wheel travel is measured using a linear potentiometer, which is mounted parallel to the damper on the rocker/bell crank. The motion of the wheel is transferred to the potentiometer via a rocker. Also, while designing the suspension geometry, the motion ratio was checked constantly and kept as constant as possible, and the changes were kept to be minimized linearly. This helps to visualize the motion of the wheel better as the vehicle takes a lap.

Following is the data obtained from the potentiometer mounted at the front of the vehicle and is shown in Figs. 15, 16 for both with and without anti-roll bar respectively:

The variation in wheel motion is reduced significantly in the latter case, hence validating the design. The $Y$-axis is in volts, and the $x$-axis plots the sample value logged by the potentiometer. The sensor converts the voltage input linearly of wheel travel in $\mathrm{mm}$. By comparing the data in Figs. 15, 16 it can be seen that after the use of the anti-roll bar, the wheel travel has been reduced significantly in corners as the data plot appears to be "smoothened" out over a range of logged points, which justifies that the roll in the given time was less as compared to the former case. The voltage fluctuates heavily during samples $28 \mathrm{k}-34 \mathrm{k}$ due to the car hitting a bump hence the wheel and anti-roll
Fig. 17 Potentiometer mounted on the vehicle

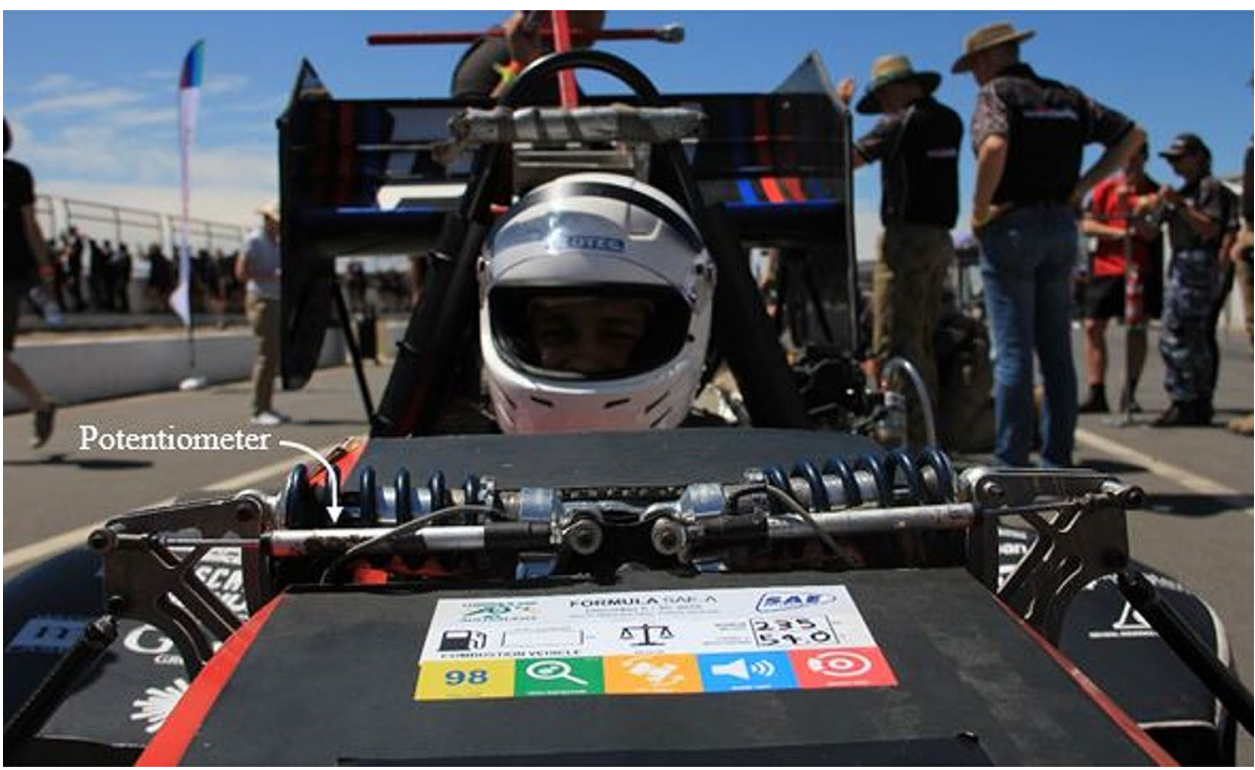

SN Applied Sciences A SPRINGER NATURE journal 
bar sustain an impact. The potentiometer mounted on the vehicle is depicted in Fig. 17.

\subsection{Static testing}

To measure the stiffness achieved by the design after manufacturing, quasi-static testing or static testing is carried out, which neglects the effects of impacts and jerks on the shaft. To measure the stiffness of the anti-roll bar, a fixture was designed to hold one end of the shaft on a rigid base. The other end was loaded gradually with a known amount of weight as shown in Fig. 18. The deflection in the moment bar was measured with a dial gauge, the correlation between the theoretical values and experimental was calculated. Experimental roll stiffness value was calculated as a known weight was applied at a fixed distance and utilizing the deflection from dial gauge using the equation as shown in Eqs. 10, 11, and 12, This equation results are depicted in Table 1.

Torque $=$ Load $*$ distance of application from center of shaft

Angular deflection $=\frac{\text { Linear deflection from dialgauge }}{\text { Distance of application of load from center of shaft }} * \frac{\pi}{180}$

Roll Stiffness $=\frac{\text { Torque }}{\text { Angulardeflection }}($ Units in $\mathrm{N}-\mathrm{m} / \mathrm{deg})$

The results from static testing depicts that the error percentage between the FEA simulation value and the
Table 1 Experimental stiffness calculation

\begin{tabular}{llll}
\hline Force(N) & Torque(N-m) & $\begin{array}{l}\text { Deflection } \\
(\mathrm{mm})\end{array}$ & Roll Stiffness \\
\hline 20 & .56 & .014 & 75.2 \\
40 & 1.12 & .02 & 75.4 \\
50 & 1.4 & .035 & 75.3 \\
60 & 1.68 & .04 & 74.8 \\
\hline
\end{tabular}

average value obtained from static testing. The deviation from simulated data $(72.3 \mathrm{~N}-\mathrm{m})$ was found to be $4 \%$ for static validation (the mean of calculated roll stiffness data, $75.175 \mathrm{~N}-\mathrm{m})$. Moreover, the error between theoretical calculation and FEA analysis was found to be $1.9 \%$ (average error between a range of forces and their corresponding deflection and roll stiffness values) which is much less than $10.62 \%$ calculated by Zhang and coworkers. [4]

\section{Conclusions}

The anti-Roll bar plays a cardinal role in a Formula Student race car, and it is a device that improves agility, stiffness, driveability, and stability without adding much weight. This research demonstrated the design, analysis, manufacturing, and testing procedure for such components. The parts designed were thoroughly scrutinized for their effectiveness, and the results were satisfactory. To analyze the results of the research, FEA was carried out on ANSYS, static testing was done in laboratory conditions and to determine the effect of the designed component

Fig. 18 Static testing setup

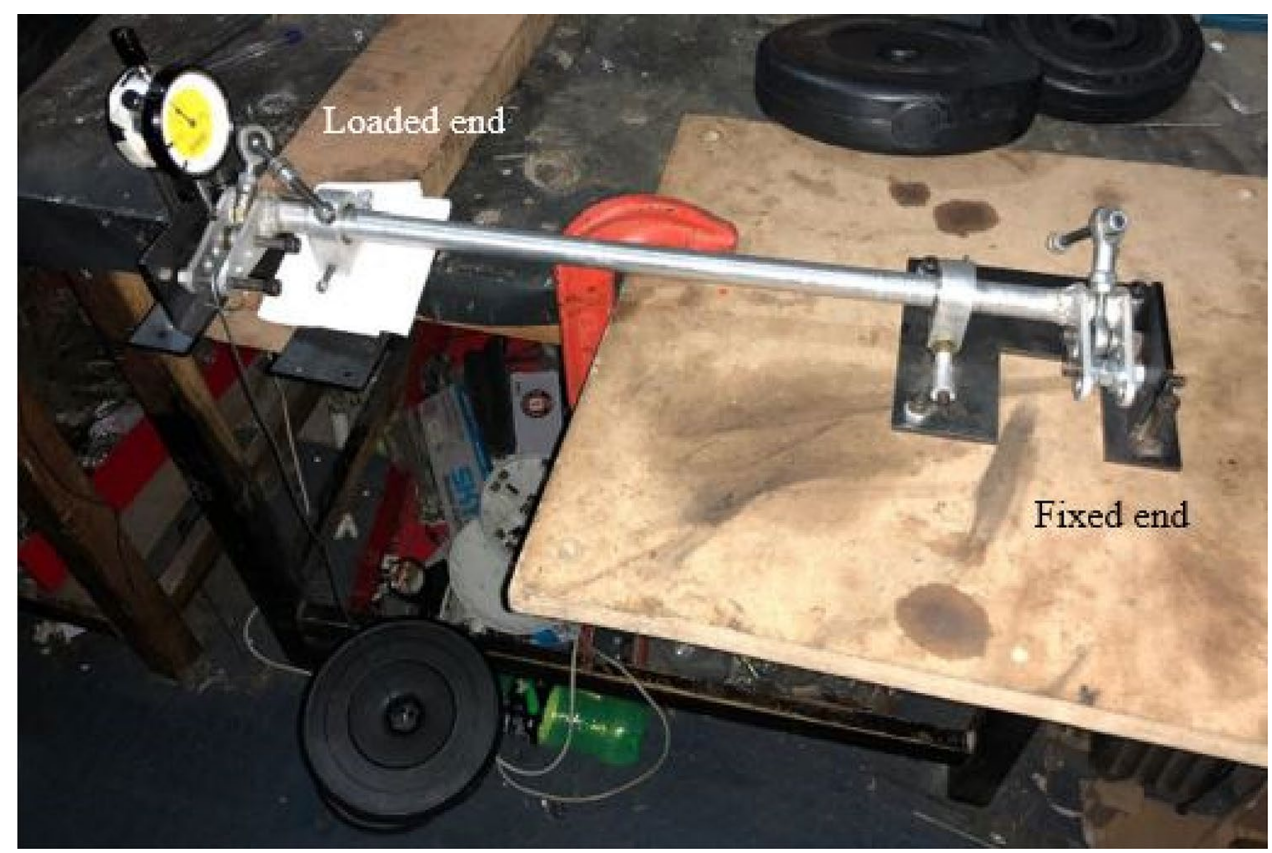


on the vehicle system on-track testing was also carried out for which the results were logged using sensors such as potentiometers. Hence based on the above results, it could be concluded that this research was carried out successfully with desired outcomes, which are within a range of acceptable values and errors. It could also be emphasized from the track testing data that the designed component desirably improves the vehicle characteristics. Despite being advantageous, it has limitations due to it being heavier in nature. In future studies on anti-roll bar, better and lighter materials like carbon fiber and others can be researched upon. Moreover, strain gauges can be used to accurately verify the stress induced in the shaft and moment arms with FEA. The future scope for the calculation and verification of this research can be an extensive comparison between FEA analysis, experiment results, and analytical calculation by utilizing different meshing parameters such as mesh sizing methods, type of transition, and quality to further optimize the FEA process and also to reduce the error between the three calculating methods. Hence converging the results to greater accuracy.

Acknowledgements We would like to express our gratitude and acknowledge the efforts, support, and dedication of the formula student team-Pravega Racing. Additionally, the completion of this research would not be possible without support from the material dealer and laser-cut partner Goodwill Industries Peenya III Phase, Bengaluru, machining, and fabrication support from GK industries and Satyamoorty; Karnataka bearings, Bengaluru. Lastly, we are grateful for the support, provision of equipment's and guidance from the staff, colleagues, and the management at VIT University.

\section{Compliance with ethical standards}

Conflicts of interest The authors have no conflicts of interest to declare that are relevant to the content of this article.

Open Access This article is licensed under a Creative Commons Attribution 4.0 International License, which permits use, sharing, adaptation, distribution and reproduction in any medium or format, as long as you give appropriate credit to the original author(s) and the source, provide a link to the Creative Commons licence, and indicate if changes were made. The images or other third party material in this article are included in the article's Creative Commons licence, unless indicated otherwise in a credit line to the material. If material is not included in the article's Creative Commons licence and your intended use is not permitted by statutory regulation or exceeds the permitted use, you will need to obtain permission directly from the copyright holder. To view a copy of this licence, visit http://creativecommons .org/licenses/by/4.0/.

\section{References}

1. Gillespie TD (1992) Fundamentals of vehicle dynamics. Society of Automotive Engineers, Warrendale, PA. ISBN: 978-1-56091-199-9
2. Mason E (2014) Alfetta_front_suspension.jpg modified to highlight anti-roll bar. https://commons.wikimedia.org/wiki/ File:Alfetta_front_suspension_antiroll.jpg Accessed 23 Jan 2021

3. Society of Automotive Engineers (1997) SAE manual on design and application of helical and spiral springs. Society of Automotive Engineers, Warrendale, PA. ISBN: 978-0-7680-0109-9

4. Zhang L, Liu H, Xu Y, Wu S, Gu L (2009) Study on Modeling Method of Anti-Roll Bar Using One Dimensional Beam Element. pp 2009-01-1454. https://doi.org/10.4271/2009-01-1454

5. Bharane MP, Tanpure MK, Kerkal MG Optimization of anti-roll bar using ansys parametric design language (APDL). https://www. semanticscholar.org/paper/Optimization-of-Anti-Roll-bar-using -Ansys-Design-Bharane-Tanpure/2f2c418f7042b5ea00288bdf0 b359f3109ad0947. http://ijergs.org/files/documents/OPTIM IZATION-85.pdf. http://citeseerx.ist.psu.edu/viewdoc/summa ry?doi=10.1.1.645.5105

6. Wang L, Xu G, Zhang N, Roser H (2013) Experimental comparison of anti-roll bar with hydraulically interconnected suspension in articulation mode. pp 2013-01-0710. https://doi. org/10.4271/2013-01-0710

7. Ribeiro SY, Silveira ME (2013) Application of finite element method in the study of variables that influence the stiffness of the anti-roll bar and the body roll. pp 2013-36-0643. https:// doi.org/10.4271/2013-36-0643.

8. Shi W, Wang C, Li Z (2015) Improving Light Bus Handling and Stability by Anti-roll Bar and Bushing Adjustment. pp 2015-010026. https://doi.org/10.4271/2015-01-0026.

9. Zhou M, Wang L, Zhang J, Zhang N (2015) Experimental investigation of interconnected hydraulic suspensions with different configurations to soften warp mode for improving off-road vehicle trafficability. pp 2015-01-0658. https://doi. org/10.4271/2015-01-0658

10. Sert E, Boyraz P (2017) Optimization of suspension system and sensitivity analysis for improvement of stability in a midsize heavy vehicle. Eng Sci Technol an Int J 20:997-1012. https:// doi.org/10.1016/j.jestch.2017.03.007

11. Kota KN, Sivanandham B (2017) Integrated model-In-Loop (MiL) simulation approach to validate active roll control system. pp 2017-01-0435. https://doi.org/10.4271/2017-01-0435

12. Zhang $Y$, Wang L, Xia R (2018) Sliding mode control of electrical active roll stabilizer using switched reluctance motor. pp 2018-01-0832. https://doi.org/10.4271/2018-01-0832

13. Liu Y, Yang K, He X, Ji X (2019) Active steering and anti-roll shared control for enhancing roll stability in path following of autonomous heavy vehicle. pp 2019-01-0454. https://doi. org/10.4271/2019-01-0454

14. Mohanavel V, lyankumar R, Sundar M, Kiran Kumar P, Pugazhendhi $L$ (2020) Modelling and finite element analysis of antiroll bar using ANSYS software. Mater Today Proc. https://doi. org/10.1016/j.matpr.2020.05.322

15. Wong JY (2008) Theory of ground vehicles, 4th ed. Wiley, Hoboken, N.J. ISBN: 978-0-470-17038-0

16. Milliken WF, Milliken DL (1995) Race car vehicle dynamics. PA, SAE International, Warrendale

17. Milliken WF, Milliken DL, Olley M (2002) Chassis design: principles and analysis. Society of Automotive Engineers, Warrendale, PA. ISBN: 978-0-7680-0826-5

18. Jazar RN (2014) Vehicle dynamics. Springer, New York

19. Hubert K, Kumar A (2005) Anti-Roll stability suspension technology. pp 2005-01-3522. https://doi.org/10.4271/2005-01-3522

20. Jack H (2013) Engineering design, planning, and management. Academic Press, Amsterdam; Boston. ISBN: 978-0-12-397771-7

21. IMiR_IA_Wyklad_11 - Statecznosc pretow prostych.pdf. http:// zwmik.imir.agh.edu.pl/dydaktyka/dla_studentow/imir/IMiR_IA Wyklad_11\%20-\%20Statecznosc\%20pretow\%20prostych.pdf. Accessed 23 Jan 2021 
22. emmetcosten (2019) FEA vs hand calculations / predicting performance before prototyping. In: aerospace structural research. https://asrengineering.com/2019/04/02/fea-vs-hand-calculatio ns/. Accessed 23 Jan 2021
Publisher's Note Springer Nature remains neutral with regard to jurisdictional claims in published maps and institutional affiliations.

\section{SN Applied Sciences}

A SPRINGER NATURE journal 